\title{
EFFECT OF NANOSILICA FROM RICE HUSK ON THE GROWTH ENHANCEMENT OF CHILI PLANT (Capsicum frutescens $L$.)
}

\author{
Pham Dinh Dung ${ }^{1}$, Le Si Ngoc ${ }^{1}$, Nguyen Ngoc Thuy ${ }^{2}$, Lu T. Minh Truc ${ }^{2}$, \\ Bui Van Le', Dang Van Phu ${ }^{3}$, Nguyen Ngoc Duy ${ }^{3}$, Nguyen Quoc Hien ${ }^{3}$ \\ ${ }^{1}$ Research and Development Center for Hi-Tech Agriculture, Cu Chi, Ho Chi Minh City \\ ${ }^{2}$ University of Science, Vietnam National University in Ho Chi Minh City, Ho Chi Minh City \\ ${ }^{3}$ Research and Development Center for Radiation Technology, Vietnam Atomic Energy Institute, \\ Ho Chi Minh City \\ "Email:ngocduy158@yahoo.com
}

Received: 17 September 2015; Accepted for publication: 19 June 2016

\begin{abstract}
Nanomaterials hold great promise of improved plant disease resistance, controlled release of agro-chemicals, enhanced plant growth, etc. In this study, the effect of nanosilica $(10-30$ $\mathrm{nm}$ ) prepared from rice husk on the growth promotion of chili plant in green house was carried out. The experiment of nanosilica treatment by foliar spraying was arranged in a factorial design with 3 replications at various nanosilica concentrations of $0,40,60$ and $100 \mathrm{ppm}$. Plant growth characteristics and chlorophyll content were assessed. Results showed that the fresh weight, dry weight, and chlorophyll content increased with the treatment of nanosilica. The optimal concentration of nanosilica was found to be of $60 \mathrm{ppm}$. Thus, treatment of nanosilica was beneficial in enhancing the growth of the chili plants.
\end{abstract}

Keywords: nanosilica, rice husk, growth, chili plant.

\section{INTRODUCTION}

Nanotechnology opens up a wide applicability in various fields like medicine, pharmaceutics, electronics and agriculture. Nanomaterials hold great promise of improved plant disease resistance, controlled release of agro-chemicals, enhanced plant growth, etc [1,2]. Silica and nanosilica from rice husk have been applied in various fields such as adsorbents, carriers, fillers, blending in Portland cement, zeolite production, drug delivery system, etc [3 - 5]. Recently, silica $\left(\mathrm{SiO}_{2}\right)$ and nanosilica from rice husk $(\mathrm{RH})$ have been also applied for production of porous ceramic for water treatment [6], and for plant growth promotion and elicitation [2, 7, 8]. RH is an agro-waste product, and about 600 million tons are generated each year around the world [9]. In Vietnam, it is estimated that rice productivity is of about 40 million tons/year. Thus, approximately 9.2 million tons of RH are generated each year. By silica content of about $10 \%$ in $\mathrm{RH}$ [10], then the silica quantity from RH resource will be nearly 1 million ton/year. Therefore, $\mathrm{RH}$ is an abundant agro-waste resource that can be used to harvest amorphous silica 
from RH ash (RHA) by burning or combustion techniques [3, 11 - 13] and nanosilica by incineration of acid treated RH $[4,14,15]$ or treatment of RHA by sol-gel method [16, 17]. So that it is also minimized the related environmental issues associated with the current applications and disposables of RH [14].

In this study, the nanosilica was prepared from RH and the effect of foliar spraying of nanosilica on growth promotion of chili plant in green house was investigated.

\section{EXPERIMENTAL}

\subsection{Materials}

Raw RH was supplied by rice mills in the south of Vietnam. Analytical reagent-grade hydrochloric acid $(\mathrm{HCl})$ was purchased from Merck, Germany. Distilled water was used throughout all experiments.

\subsection{Preparation of nanosilica from rice husk}

The process of nanosilica preparation was adopted from the method as described by Athinarayanan et al. [4] and Wang et al. [14] with some modifications. Briefly, raw RH was first rinsed with water to remove dusts, soluble substances, and other contaminants. It was then dried at $60{ }^{\circ} \mathrm{C}$ in forced air oven (Yamato, DNF 410, Japan). Approximately $50 \mathrm{~g}$ of the dried $\mathrm{RH}$ was then treated with $500 \mathrm{ml}$ of $1 \mathrm{~N} \mathrm{HCl}$ at ambient temperature for $2 \mathrm{~h}$ by magnetic stirring. It was cooled and kept intact overnight. Then it was decanted and thoroughly washed with distilled water until the rinse became free from acid. The treated $\mathrm{RH}$ was subsequently dried in forced air oven until to dry. The resulted RH was ground into fine powder. The obtained RH powder was incinerated at $700{ }^{\circ} \mathrm{C}$ for $2 \mathrm{~h}$ inside a programmable furnace (Nabertherm $\mathrm{GmbH}$, Germany) to obtain nanosilica.

\subsection{Characterization of nanosilica}

The silica content and the amount of metallic impurities in the sample were estimated by energy dispersive $\mathrm{x}$-ray spectrometer (EDX), Horiba 7593-H. The X-ray diffraction (XRD) pattern of nanosilica was recorded on an X-ray diffractometer, D8 Advance A25, Brucker, Germany. The particle size of nanosilica was performed using transmission electron microscopy (TEM), model JEM1010, JEOL, Japan.

\subsection{Growth promotion of nanosilica for chili plant}

The 60-day old chili plants (Capsicum frutescens L.) were designed for 4 treatments with 3 replications of foliar spraying nanosilica namely: control (treated with water without nanosilica), 40, 60 and $100 \mathrm{ppm}$ of nanosilica in green house of Hi-Tech Agriculture Center, $\mathrm{Cu} \mathrm{Chi}$, Ho Chi Minh City at $30 \pm 2{ }^{\circ} \mathrm{C}$ and $\mathrm{RH}$ of $60 \pm 2 \%$. The number of chili plants used in 4 treatments mentioned above was of 120 plants (30 plants/treatment). After two spraying times (two weeks), the chili plants were continued to grow for further 3 weeks. Then the fresh weight, the dried weight and the chlorophyll content were investigated. Chlorophyll $(a+b)$ content was spectrophotometrically determined using alcohol extraction according to the method as described by Dere et al. [18]. Statistical analyses of data were conducted according to method of field experiment by one-way ANOVA processing with $\mathrm{P}<0.05$ [19]. 


\section{RESULTS AND DISCUSSION}

\subsection{Nanosilica from rice husk}

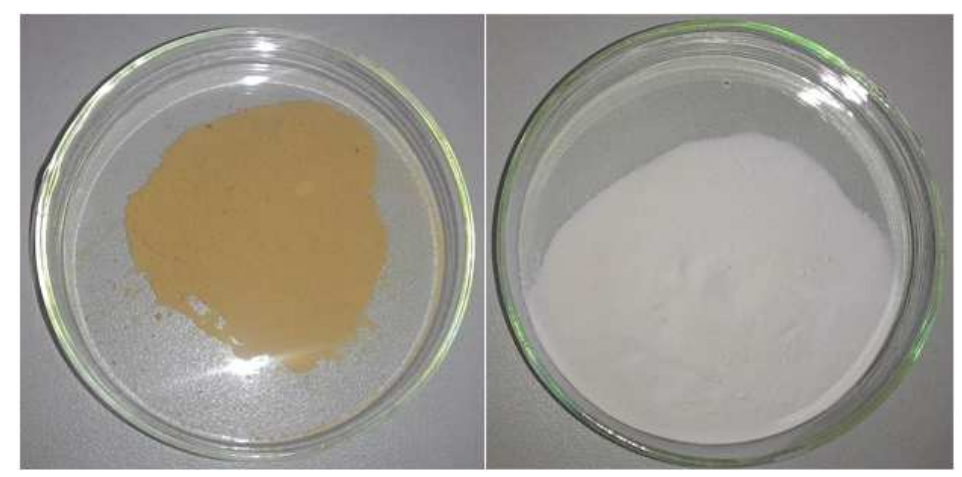

Figure 1. Photograph of RH powder ((left) and nanosilica from RH powder (right).

In this study, while nanosilica in Figure 1 with the yield of $10.21 \pm 0.38 \%$ was prepared from RH powder using acid treatment and subsequent incineration at $700{ }^{\circ} \mathrm{C}$ for $2 \mathrm{~h}[4,14]$.

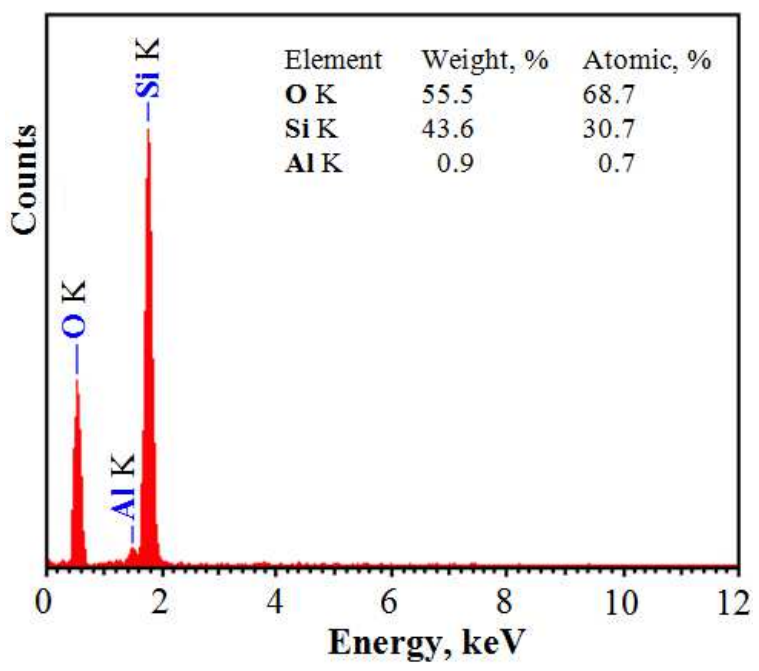

Figure 2. EDX spectrum of nanosilica from RH powder.

According to Le et al., Vietnamese $\mathrm{RH}$ ash without acid treatment consists of $\mathrm{K}_{2} \mathrm{O}(0.39$ $\%), \mathrm{Al}_{2} \mathrm{O}_{3}(0.48 \%), \mathrm{Fe}_{2} \mathrm{O}_{3}(0.15 \%), \mathrm{CaO}(0.73 \%), \mathrm{MgO}(0.55 \%), \mathrm{Na}_{2} \mathrm{O}(0.12 \%)$ and $\mathrm{SiO}_{2}$ (96.15\%) [16]. In this study, RH (not RH ash) was treated with $1 \mathrm{~N} \mathrm{HCl}$ before incineration, therefore the metallic impurities were efficiently removed. Only $\mathrm{Al}_{2} \mathrm{O}_{3}\left(\mathrm{k}_{\alpha}\right.$ at $\left.1.486 \mathrm{keV}\right)$ still remained in small content of $0.7 \%$ calculated as atomic percentage (Figure 2). Value of $\mathrm{k}_{\alpha}$ of silicon $(\mathrm{Si})$ and oxygen $(\mathrm{O})$ in EDX spectrum presented in Figure 2 is of 1.739 and $0.525 \mathrm{keV}$, respectively. In addition, Carmora et al. reported that organic acids namely acetic and citric acid can be also used to remove metallic impurities efficiently [15]. 


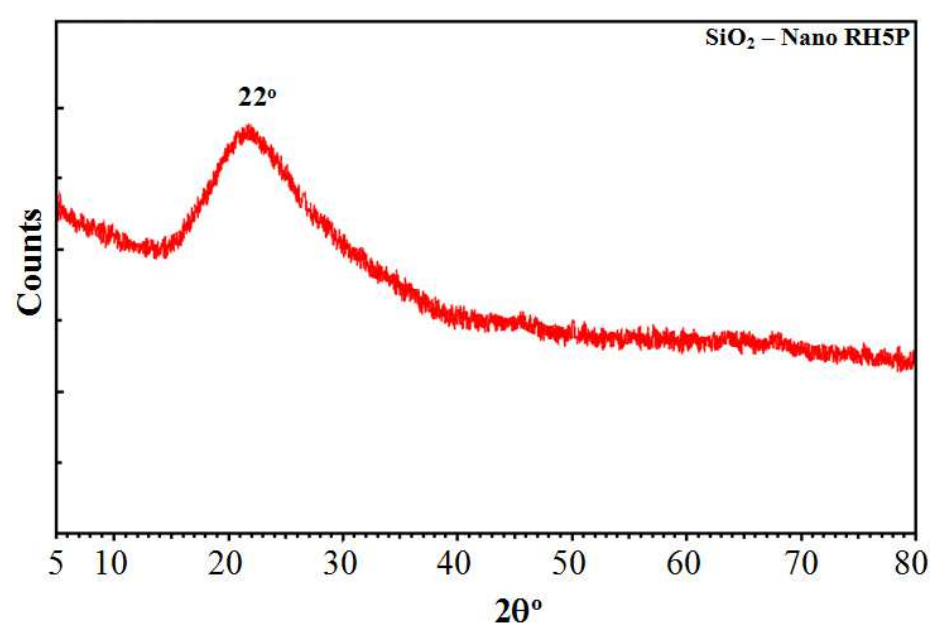

Figure 3. XRD pattern of nanosilica from RH powder.

The XRD pattern of the nanosilica was shown in Figure 3. It can be observed from Figure 3 that the only one peak at $2 \theta \approx 22^{\circ}$ confirmed the purity and amorphous structure of nanosilica generated from acid treated $\mathrm{RH}$ powder $[4,14,16]$.

The size of as-prepared nanosilica was estimated from TEM image in Figure 4 to be of 10 $30 \mathrm{~nm}$. Athinarayanan et al. also reported the same size of nanosilica harvested by incineration of $\mathrm{RH}$ powder at $700{ }^{\circ} \mathrm{C}$ for $2 \mathrm{~h}$, while incineration at lower temperature particularly at 500 and $600{ }^{\circ} \mathrm{C}$ generated nanosilica with larger size [4].

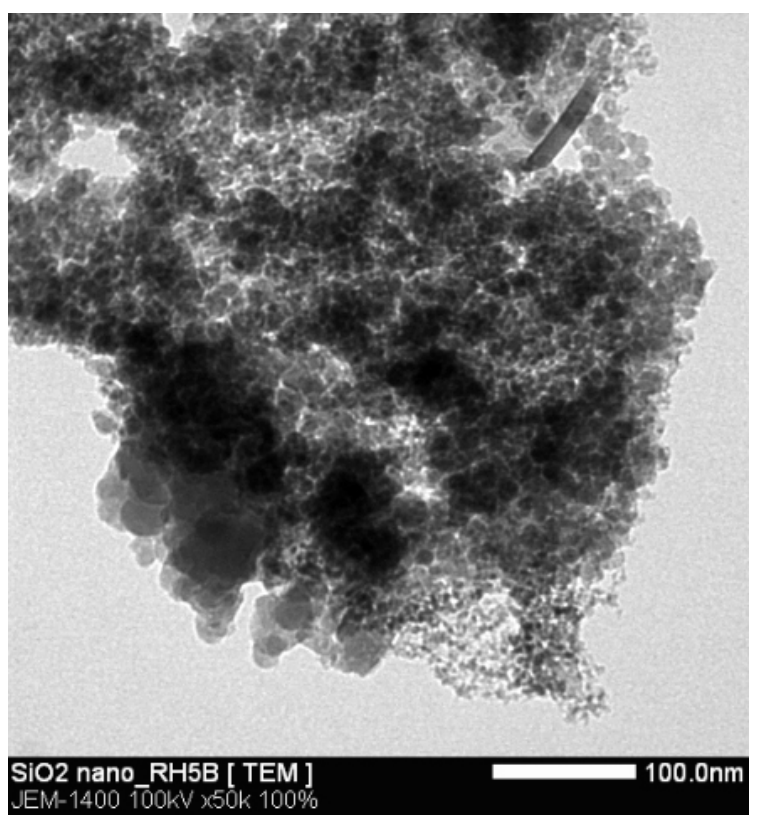

Figure 4. TEM image of nanosilica from RH powder.

\subsection{Growth characteristics of chili plant treated with nanosilica}


Table 1. Effect of nanosilica on growth parameters in chili plant after 35 days of growth.

\begin{tabular}{|c|c|c|c|c|c|}
\hline \multirow{2}{*}{$\begin{array}{c}\text { Nanosilca } \\
\text { Treatment }\end{array}$} & \multicolumn{2}{|c|}{ Shoot biomass, g/plant } & \multicolumn{2}{|c|}{ Root biomass, g/plant } & \multirow{2}{*}{$\begin{array}{c}\text { Chlorophyll } \\
(\mathrm{a}+\mathrm{b}), \mathrm{mg} / \mathrm{g}\end{array}$} \\
\cline { 2 - 5 } & Fresh weight & Dry weight & Fresh weight & Dry weight & \\
\hline Control & $25.67 \mathrm{~d}^{*}$ & $6.50 \mathrm{~d}^{*}$ & $3.52 \mathrm{~b} *$ & $0.38 \mathrm{c}^{*}$ & $21.29 \mathrm{~d}^{*}$ \\
\hline $40 \mathrm{ppm}$ & $28.78 \mathrm{~b}$ & $7.51 \mathrm{c}$ & $4.24 \mathrm{a}$ & $0.47 \mathrm{~b}$ & $24.61 \mathrm{c}$ \\
\hline $60 \mathrm{ppm}$ & $30.17 \mathrm{a}$ & $12.34 \mathrm{a}$ & $4.59 \mathrm{a}$ & $0.55 \mathrm{a}$ & $36.67 \mathrm{a}$ \\
\hline $100 \mathrm{ppm}$ & $28.16 \mathrm{c}$ & $11.51 \mathrm{~b}$ & $4.14 \mathrm{a}$ & $0.45 \mathrm{~b}$ & $25.42 \mathrm{~b}$ \\
\hline$* * \mathrm{LSD}_{0.05}$ & 0.13 & 0.53 & 0.61 & 0.03 & 0.55 \\
\hline
\end{tabular}

*Different letters in the same column indicate significant differences at $P<0.05$.

**Least significant difference $(L S D)$ at $P<0.05$.

From the results in Table 1, it indicated clearly that the treatment of $60 \mathrm{ppm}$ of nanosilica was found to be the best for the growth enhancement of chili plant, particularly the fresh weight of shoot and root increased to $17.5 \%$ and $30.4 \%$, and the dry weight of shoot and root increased to $\sim 90 \%$ and $44.7 \%$, respectively compared to that of the control (spraying with water). In addition, the total chlorophyll $(\mathrm{a}+\mathrm{b})$ content increased remarkably to $70.6 \%(36.67 \mathrm{mg} / \mathrm{g})$ in comparison with that of the control $(21.29 \mathrm{mg} / \mathrm{g})$. The present results also showed that the increase in chlorophyll content by the treatment of nanosilica on chili plants resulted in higher photosynthetic rate [20]. The obtained results also suggested that treatment of nanosilica had a beneficial effect on photosynthesis. Suriyaprabha et al. reported that treatment of $15 \mathrm{~kg} / \mathrm{ha}$ nanosilica from RH in soil showed the better growth promotion of maize in terms of stem height and chlorophyll content compared with other treatments and control one [7]. They concluded that the application of nanosilica fertilizers in soil was more superior to bulk silica and control for growth enhancement of maize. Siddiqui et al. also reported that treatment of nanosilica ( 8 $\mathrm{g} / \mathrm{L}$ ) of tomato seeds significantly enhanced the characteristics of seed germination, and seedling fresh weight and dry weight [8]. Based on the results obtained by Suriyaprabha et al. [7], Siddiqui et al. [8] and our results in the present study, it suggests that nanosilica could be used as a fertilizer either by foliar spraying and/or by soil amendment for crop improvement with better yield. In addition, it is interesting to note that treatment of nanosilica is also able to protect the plant from pathogenic infection [2]. Furthermore, the results of Rodrigues et al. proved that silica played an active role in the resistance of rice to blast disease by induction of phytoalexins [21]. Recently, Kiirika et al. reported that combined treatment of silica and chitosan induced the synergistic effect against bacterial disease for plant (tomato) [22]. Thus, nanosilica is promising to apply as growth promoter and elicitor for plants.

\section{CONCLUSION}

Nanosilica $(10-30 \mathrm{~nm})$ from RH was successfully prepared by incineration of acid treated $\mathrm{RH}$ powder at $700{ }^{\circ} \mathrm{C}$ for $2 \mathrm{~h}$. By foliar spraying, nanosilica of $60 \mathrm{ppm}$ showed the best growth enhancement of chili plant in terms of the increase of fresh weight, dry weight and chlorophyll content. Thus, nanosilica from RH is promising to apply as growth promoter and elicitor for plants as well as an environmentally friendly agro-chemical for sustainable development of agriculture. 
Acknowledgments. This research was partly supported by Research and Development Center for Hi-Tech Agriculture, $\mathrm{Cu}$ Chi, Ho Chi Minh City.

\section{REFERENCES}

1. Khot L.R. et al. - Applications of nanomaterials in agricultural production and crop protection: A review, Crop. Proct. 35 (2012) 64-70.

2. Huang S. et al. - Nanotechnology in agriculture, livestock, and aquaculture in China. A review, Agron. Sustain. Dev. (2014) DOI 10.1007/s13593-014-0274-x.

3. Chandrasekhar S. et al. - Processing, properties and application of reactive silica from rice husk-an overview, J. Mater. Sci. 38 (2003) 3159-3168.

4. Athinarayanan J. et al. - Synthesis of biogenic silica nanoparticles from rice husks for biomedical applications, Ceramics Inter. 41 (2015) 275-281.

5. Pode R. - Potential applications of rice husk ash waste from rice husk biomass power plant, Renew. Sust. Energ. Rev. 53 (2016) 1468-1485.

6. Nguyen T.A.T. et al. - Bactericidal activity and silver release of porous ceramic candle filter prepared by sintering silica with silver nanoparticles/zeolite for water disinfection, Adv. Nat. Sci.: Nanosci. Nanotechnol. 5 (2014) 035001.

7. Suriyaprabha R. et al. - Growth and physiological responses of maize (Zea mays L.) to porous silica nanoparticles in soil, J. Nanopart. Res. 14 (2012)1294.

8. Siddiqui M.H, Al-Whaibi M.H - Role of nano- $\mathrm{SiO}_{2}$ in germination of tomato (Lycopersicum esculentum seeds Mill.), Saudi J. Biol. Sci. 21 (2014) 13-17.

9. Feng Q. et al. - Adsorption of lead and mercury by rice husk ash, J. Colloid Interface Sci. 278 (2004) 1-8.

10. Liou T.H. - Preparation and characterization of nano-structured silica from rice husk, Mater. Sci. Eng. A 364 (2004) 313-323.

11. Habeeb G.A., Mahmud H.B. - Study on properties of rice husk ash and its use as cement replacement material, Mater. Res. 13 (2010) 185-190.

12. Della V.P., Kuhn I., Hotza D. - Rice husk ash as an alternative source for active silica production, Mater. Lett. 57 (2002) 818-821.

13. Fernandes I.J. et al. - Characterization of rice husk ash produced using different biomass combustion techniques for energy, Fuel 165 (2016) 351-359.

14. Wang W. et al. - Harvesting silica nanoparticle from rice husk, J. Nanopart. Res. 13 (2013) 6981-6990.

15. Carmona V.B. et al. - Nanosilica from rice husk: Extraction and characterization, Ind. Crops Prod. 43 (2013) 291-296.

16. Le V.H et al. - Synthesis of silica nanoparticles from Vietnamese rice husk by sol-gel method, Nanoscale Res. Lett. 8 (2013) 58.

17. Rafiee E. et al. - Optimization of synthesis and characterization of nanosilica produced from rice husk (a common waste material), Inter. Nano Lett. 2 (2012) 29.

18. Dere S. et al. - Spectrophotometric determination of chlorophyll-a,b and total carotenoid contents of some algae species using different solvents, Tr. J. Botany 22 (1998) 13-17, 1998. 
19. Pham Chi Thanh - Method for field experiment, Agric. Publisher, Hanoi, 1976.

20. Ma L. et al. - Alleviation of exogenous oligochitosan on wheat seedlings growth under salt stress, Protoplasma (2011) DOI 10.1007/s00709-011-0290-5.

21. Rodrigues F.A. et al. - Silicon enhances the accumulation of diterpenoid phytoalexins in rice: a potential mechanism for blast resistance, Biochem. Cell Biol. 94 (2004) 177-183.

22. Kiirika L.M. et al. - Phenotypic and molecular characterization of resistance induction by single and combined application of chitosan and silicon in tomato against Ralstonia solanacearum, Physiol. Mol. Plant Pathol. 81 (2013) 1-12. 